\title{
As meninas estão na rede: a inclusão digital na terceira idade
}

\author{
Larissa Medianeira Bolzan* \\ Mauri Leodir Löbler ${ }^{* *}$
}

\section{Resumo}

Neste estudo, buscou-se compreender como ocorre o processo de inclusão digital de idosos com base nas percepções de indivíduos participantes de um grupo de terceira idade que usa a inclusão digital como ferramenta para a inclusão social. Para atingir o objetivo, realizou-se uma pesquisa de caráter etnográfico. Como resultados, destacaram-se descobertas como o processo de afetização e socialização que ocorre durante o período destinado à construção de conhecimento sobre as tecnologias de informação e comunicação (TICs). No que se refere ao impacto da inclusão digital na vida dos idosos, percebeu-se o aumento do nível de autoestima. Os indivíduos que participaram da proposta da política pública tornaram-se mais confiantes frente à tecnologia, à sociedade e à família.

Palavras-chave: Inclusão digital. Etnografia. Inclusão social.

\section{Introdução}

O perfil etário da população brasileira tem apresentado mudanças notórias, tal como o perfil da população mundial. De acordo com os dados divulgados pela Organização Mundial da Saúde (OMS), a expectativa de vida aumenta a cada ano. Atualmente, o Brasil encontra-se no grupo dos dez países com maior índice de idosos, sendo importante destacar que o contexto em que ocorreu o aumento da população idosa foi o de um intensivo progresso tecnológico.

De acordo com Muraro (2009), o século XX assistiu e o XXI está assistindo à mais fantástica revolução histórica da humanidade, que não se trata de uma revolução política, social ou econômica, mas sim de uma revolução humana, em sua totalidade, centrada no desenvolvimento da ciência e da tecnologia. Conforme

\footnotetext{
Recebido: 05/05/2013 - Aprovado: 02/07/2013

http://dx.doi.org/10.5335/rep.2013.3557
}

Mestra e Graduada em Administração pela Universidade Federal de Santa Maria. Doutoranda em Administração pela Universidade Federal do Rio Grande do Sul. E-mail: larissambolzan@gmail.com.

* Professor Adjunto do Departamento de Ciências Administrativas da Universidade Federal de Santa Maria. Doutor em Administração pela Universidade Federal do Rio Grande do Sul. Mestre em Engenharia de Produção pela Universidade Federal de Santa Maria. Graduado em Administração pela mesma instituição. E-mail: mllobler@gmail.com. 
o entendimento de Goldfarb (1997), a evolução tecnológica provoca mudança de valores com relação ao simbolismo da transcendência existencial.

No atual contexto da sociedade brasileira, estereótipos negativos são enfrentados pelos idosos; muitos sofrem preconceito devido à familiaridade limitada acerca das tecnologias de informação e comunicação (TICs) (FREITAS; PASSERINO, 2012), situação que os leva a buscar conhecimento sobre o assunto.

O aprendizado sobre TICs ocorre de forma mais concentrada e planejada por meio de políticas públicas de inclusão digital, existindo algumas voltadas ao idoso. A importância de os indivíduos caracterizados como idosos participarem de grupos que promovem aprendizado reside no fato de que nesses espaços é possível buscar a inclusão social, ou seja, resgatar a estima de existir para o outro (FREITAS; PASSERINO, 2012).

Este trabalho descreve uma etnografia em um grupo de terceira idade que busca a inclusão social usando a apropriação do conhecimento sobre o computador como ferramenta. Ou seja, esta investigação apresenta considerações a respeito das percepções dos idosos diante da inclusão digital como meio para atingir a inclusão social.

Assim, o objetivo desta pesquisa é compreender como ocorre o processo de inclusão digital de idosos com base nas percepções de indivíduos participantes de um grupo de terceira idade que usa a inclusão digital como ferramenta para socialização. Já os seus objetivos específicos são: (i) investigar como o processo de inclusão digital é vivenciado pelos indivíduos que são foco desse processo; e (ii) compreender as influências de um programa de inclusão digital no processo de socialização dos indivíduos.

O conceito de inclusão digital utilizado neste trabalho é uma compilação proposta por Löbler et al. (2011), que considera o processo de inclusão digital dinâmico, o qual, por meio do acesso às TICs, torna possível a apropriação do conhecimento sobre essas tecnologias para que o indivíduo possa desenvolver e aperfeiçoar habilidades capazes de propiciar autonomia sobre as ferramentas digitais e sua utilização crítica. É imprescindível, também, que o processo de inclusão digital possibilite o aprimoramento da interação, ou seja, a atualização do conhecimento.

Buscando ampliar esse espaço de discussão sobre a inclusão digital, esta pesquisa foi desenvolvida, inicialmente, com o objetivo de aprofundar teorizações concernentes a políticas públicas de inclusão digital. Em termos metodológicos, foi utilizada a investigação etnográfica, pois o intuito do estudo exigia uma pesquisa em profundidade, de modo que se optou pela apresentação de vivência em um curso de informática básica, visando à inclusão digital de idosos. Finalmente, envolveu-se o trabalho na discussão dos achados em campo com as teorias pertinentes. 


\section{A inclusão digital na terceira idade}

Ao falar em idoso, cabe apresentar uma definição, já que, de acordo com Goldfarb (1997), o processo de envelhecimento torna o indivíduo um ser mutante. "A principal dificuldade para categorizar a velhice consiste em ela não ser unicamente um estado, mas um constante e sempre inacabado processo de subjetivação. Assim, podemos dizer que, na maior parte do tempo, não existe um ser velho, mas um ser envelhecendo" (GOLDFARB, 1997, p. 9, grifo do autor).

É possível, então, arriscar uma definição psicológica. Para muitas teorias, o envelhecimento e a velhice estão relacionados ao tempo kairótico, que trata do entendimento do tempo que cada um viveu, ou seja, um tempo psicológico que dita o modo como lidaremos com o processo de envelhecimento, considerando o enrijecimento do processo cognitivo do idoso e as restrições sensoriais próprias do envelhecimento (GOLDFARB, 1997; KACHAR, 2003, 2009; GOLDFARB et al., 1997; PEREIRA; NEVES, 2011). Conforme a Lei $n^{\circ}$ 10.742, de $1^{\circ}$ de outubro de 2003, idoso é todo indivíduo com 60 anos ou mais.

Segundo Goldfarb $(1997,2009)$, outras características desse período da vida são: a perda de entes queridos, o aparecimento de rugas e cabelos brancos, as patologias clássicas do envelhecimento (como osteoporose, artrose, hipertensão, cardiopatias, dentre outras).

$\mathrm{O}$ atual modelo contemporâneo de sociedade exalta a figura do jovem como um ser belo, forte e poderoso, destinando aos idosos o dolo da incapacidade e da impotência. A violência exercida pelo discurso enaltecendo a juventude indica uma falta de reconhecimento social para com a velhice, adverte a carência de um lugar simbólico para o idoso, levando a que uma condição desejante de inclusão social seja buscada ao envelhecer (GOLDFARB, 1997).

Uma das diferenças mais gritantes entre o comportamento de jovens e idosos encontra-se no entendimento e no manuseio de TICs. A geração de idosos de hoje tem revelado inúmeras dificuldades acerca de entender a nova linguagem da sociedade, a linguagem digital (KACHAR, 2003). Para esse autor, compreender os avanços tecnológicos, até mesmo nas questões mais básicas como o funcionamento dos eletrodomésticos, celulares, caixas eletrônicos, é uma barreira para a inclusão social de um idoso. Assim, o interesse dos integrantes dessa faixa etária em aprender a manusear as TICs surge da necessidade de sentirem-se inseridos na sociedade moderna, de não se sentirem marginalizados perante esta e, também, como forma de aproximação da família e dos amigos de gerações mais novas (FREITAS; PASSERINO, 2012). 
Nesse sentido, Pereira e Neves (2011) desenvolveram uma metodologia pedagógica para ensinar idosos levando em consideração características específicas como idade, background, meio social e cultural. Segundos os autores, "mais especificamente, no que concerne ao ensino das TICs a idosos, é necessário promover um ambiente de aprendizagem próprio para os indivíduos em questão, que passa pela criação de uma interação com a máquina, de acordo com as suas necessidades e condições físicas" (2011, p. 5).

Do ponto de vista de Freedman, Carlsmith e Sears (1970), políticas públicas que promovem a inclusão digital de idosos proporcionam a sua socialização, coerente com o ambiente em que eles se propuseram a estar - o escolar. Esse espaço predispõe o idoso, também, à afetização, uma vez que a dimensão afetiva não expressa a "natureza" dos indivíduos, mas sim as situações das suas vivências, que mobilizam vocabulários, expressões e formas de participação social (LE BRETON, 2009).

Kachar (2003) enfatiza a importância de manter atenção ao processo cognitivo do idoso, pois o ritmo de cognição é mais lento e há, ainda, as restrições sensoriais próprias do envelhecimento. A mesma autora (2009) discute que, nos processos pedagógicos, devem ser consideradas as dificuldades quanto à virtualidade do idoso, sendo fundamental adaptar o curso às particularidades do grupo. O ideal é que os encontros ocorram semanalmente e comportem em torno de duas horas diárias, com turmas pequenas que não ultrapassem 15 alunos e, preferencialmente, com um aluno por computador, pois as solicitações de orientação e dúvidas do aprendiz na terceira idade são maiores.

Com relação às explicações, é preciso desenvolver um ritmo brando, contínuo e progressivo de complexidade, fornecendo informações gradativamente, pois muitas informações simultâneas podem gerar confusão e estresse, levando à desmotivação e à desistência, além da frustração e sensação de incapacidade para compreender essa linguagem (WEHMEYER, 2006; KACHAR, 2009).

Além disso, é importante investir em repetições de tarefas, estimulando a memória do idoso (KACHAR, 2009). Segundo a autora, o conteúdo deve atender às necessidades de compreensão da linguagem digital e, também, ao funcionamento dos recursos básicos do processador de textos, da pesquisa na internet e do endereço eletrônico (e-mail), procurando garantir habilidade mínima no exercício da autonomia com a tecnologia.

No que se refere às dificuldades encontradas por grupos de terceira idade acerca do aprendizado sobre as TICs, citam-se os lapsos de memória, menor velocidade de raciocínio e limitação motora (KACHAR, 2009; DRIUSSO; CHIARELLO, 2007 apud MENDONÇA; MACEDO, 2010). 
Quanto a resultados positivos identificados em trabalhos que promoveram a inclusão digital de idosos, destaca-se na literatura o nível de autoestima. Luzzi (2006), Xavier (2007), Fraquelli (2008), Bersch (2009), Kachar (2009), Griebler, Rokoski e Dalri (2010), Marcon (2010), Wolf et al. (2010), Granda e Duarte (2011), Ordones, Yassuda e Cachioni (2011), Passos e Abreu (2011), Pereira e Neves (2011) e Bolzan, Oliveira e Löbler (2013) discutem que a inclusão digital pode promover melhoria da autoestima, fazendo os idosos sentirem-se valorizados perante a família e a sociedade.

\section{Método de estudo}

Este trabalho consiste no recorte de uma dissertação de mestrado que buscou conhecer o processo de inclusão digital sob o ponto de vista do indivíduo que procura construir conhecimento sobre as TICs. No que se refere ao método, o estudo caracteriza-se por vincular-se ao paradigma interpretativista. Estudos que pertencem a essa abordagem, segundo Burrell e Morgan (1979), têm como características a subjetividade, a busca de compreensão de um fenômeno social, o estudo do objeto em profundidade e a exploração de um fenômeno a fim de gerar conhecimento a respeito de um tema ainda pouco explorado (BURRELL; MORGAN, 1979; MORGAN, 1980; CASALI, 2004).

Ainda no que diz respeito ao método, utilizou-se a perspectiva etnográfica. Característica em estudos antropológicos, esta permite a captação de fenômenos na sua essência e comporta entender um fenômeno dentro da realidade em que acontece, pois envolve a participação direta do pesquisador (CAVEDON, 2008). Segundo Malinowski, ao utilizar o método etnográfico, o pesquisador é, ao mesmo tempo, "o seu próprio cronista e historiador; suas fontes de informação são, indubitavelmente, bastante acessíveis, mas também extremamente enganosas e complexas" (1978, p. 18).

Para a coleta de dados da presente pesquisa, foram utilizadas observação participante e entrevistas semiestruturadas. É importante destacar que o bom-humor, o clima de solidariedade e o respeito estiveram presentes todo o tempo. Isso não é tratado como uma limitação da pesquisa, ao contrário, como fator contribuinte na compreensão de como ocorre o processo de inclusão digital "de corpo e alma", conforme diria Wacquant (2002), permitindo uma prévia dos resultados intersubjetivos de um trabalho científico que engloba os - e vai além dos - objetivos da pesquisa.

A inserção e a naturalização nesse campo deram-se como pesquisadora, tendo-se, desde o primeiro contato, deixado clara a intenção de observar como ocorria a 
inclusão digital no projeto. Salienta-se que, na construção do texto, foi privilegiada a polifonia, ou seja, o texto foi construído pela voz da pesquisadora, pela voz do campo no qual se inseriu e, para legitimar a discussão, pela voz de teóricos a respeito do tema. Logo, buscou-se tornar identificáveis as categorias êmico, ético e teórico. Em relação aos sujeitos da pesquisa, utilizam-se nomes fictícios quando estes são apresentados ao longo do texto.

\section{0 processo de inclusão digital na terceira idade proposto por uma política pública}

A procura dos idosos pelo projeto, pela inclusão digital deu-se devido ao fato de sentirem-se excluídos dos assuntos e dos contatos com a família e grupos de amigos. Depoimentos como "meu neto tenta me ensinar, mas não tem paciência, daí ele diz: ahh vó, tu é burra, sai daî", "Cuidado que tu vai quebrar" eram bastante comuns durante as interações. Essas situações de preconceito e violência são consideradas naturais para Freitas e Passerino (2012), uma vez que a maioria das pessoas acredita que os idosos não têm interesse em aprender sobre TICs e/ou utilizá-las.

Nessa política pública, as educandas, 11 senhoras, em sua maioria professoras aposentadas, eram chamadas de forma carinhosa pela denominação de meninas. A esse respeito, cabe uma relação com o estudo de Locatelli e Cavedon (2011) que identificou o uso da expressão gurias em referência a um grupo de hidroginástica composta por idosas na capital gaúcha. Conforme Goldfarb (1997), é comum o eufemismo para nomear o envelhecimento e tudo que a ele remete. De acordo com o autor, trata-se de uma tentativa falida de suavizar o peso que a palavra "velho" causa na consciência da nossa sociedade.

Nessa etnografia, o educador era responsável pelo planejamento e pela condução do conteúdo. A dinâmica das aulas era a apresentação do procedimento mediante sua verbalização, complementada por figuras que o educador desenhava na lousa; em seguida, era permitido e incentivado o treinamento por parte dos alunos no computador.

A sala onde ocorriam os encontros, que promovia a inclusão digital, era equipada com 18 computadores doados. Essas máquinas eram antigas, desatualizadas e não passaram por revisão antes de serem utilizadas como objeto de estudo, ocasionando falhas no funcionamento. A relação entre o número de computadores em funcionamento e o número de alunos que frequentavam as aulas obrigava a formação de duplas e troca de computadores, devido a possíveis defeitos e/ou desatualizações de software ou hardware. 
Cabe ressaltar, no entanto, que o transtorno quanto à troca de lugares para o uso de outro computador não desmotivava as alunas. Em determinado encontro, Esther precisou trocar de lugar quatro vezes e, na quarta vez, exclamou: "vamos lá com esse professor bom, para a gente aprender um monte de coisas boas" (fala de Esther, anotações do Diário de Campo do dia 16 de outubro de 2012). Já a formação de duplas gerava desconforto para algumas educandas, pois acreditavam ser necessária a interação com o computador para que houvesse aprendizado.

A construção do conhecimento sobre as TICs dava-se em uma dinâmica semelhante ao ciclo de Kolb (1978), na medida em que os alunos captavam a nova informação por meio da explicação, refletiam a respeito da informação absorvida e mudavam ou adaptavam seu comportamento durante a tarefa, visando a completar o aprendizado mediante treino com o computador. Nas entrevistas, Iberê, uma aluna, disse que "mexer no computador depois que o professor explica faz toda a diferença, ajuda muito, é por isso que se aprende". Eliane, outra aluna, afirmou: "a gente só aprende se a gente treinar no computador". Durante a entrevista, ela destacou que cada um não poder usar um computador limita o aprendizado, porque "um faz e os que ficam olhando não aprendem", enfatizando a limitação da infraestrutura tecnológica oferecida, também citada, na entrevista, pelo professor, por Iberê e por Édna.

O princípio de ancoragem de Ausubel foi uma estratégia utilizada pelo educador para potencializar o aprendizado. De acordo com a teoria ausubeliana, o aprendizado dá-se por meio do princípio de ancoragem, ou seja, um conceito conhecido é usado como âncora para captação de uma nova informação (AUSUBEL, 1978).

Dentre as dificuldades enfrentadas pelas educandas, destaca-se o fato de não lembrarem o procedimento das atividades já realizadas, mesmo que várias vezes. Isso pode ser justificado em razão de os indivíduos na terceira idade, geralmente, apresentarem lapsos de memória e menor velocidade de raciocínio (KACHAR, 2009; DRIUSSO; CHIARELLO, 2007 apud MENDONÇA; MACEDO, 2010).

Outra dificuldade observada foi o controle do mouse, o que acarretava problemas acerca da abertura de um programa ou arquivo, pois o clique duplo também é uma dificuldade. Na entrevista, Eliane revela que não consegue "dar os dois cliques porque escorrega". A seleção de textos e o clicar em algumas opções de formatação são atividades consideradas bastante difíceis, também devido à dificuldade com o mouse.

Essa limitação foi igualmente evidenciada nos estudos de Wehmeyer (2006), Kachar (2009), Marcon (2010), Pereira e Neves (2011), Bolzan et al. (2012) e Bolzan, Oliveira e Löbler (2013). Os referidos autores afirmam que a dificuldade motora com o mouse é a primeira observada em aprendizes que não têm contato com o computador. 
Outro comportamento que se repetia eram os cliques sucessivos no mouse quando o computador "demorava para responder". Nesse sentido, Franco (2003), pondera que, muitas vezes, o sentimento de impotência diante de uma situação rotineira com relação à tecnologia tende a provocar ansiedade, e é essa ansiedade que provoca os cliques sucessivos.

No que tange às dificuldades encontradas pelos idosos, ao apropriarem-se do conhecimento acerca das TICs, Pereira e Neves (2011) discutem que cabe ao educador suavizá-las, respeitando o ritmo de cada educanda, cedendo um maior período de tempo para a execução de tarefas, promovendo descansos frequentes e a repetição das atividades.

Quanto ao comportamento, cabe destacar a boa relação que existia entre as alunas. No início da aula, conforme iam chegando, cumprimentavam-se com abraços e beijos no rosto. Aquelas que tinham um laço de amizade já consolidado ou um assunto em comum procuravam sentar-se próximas, ou seja, usar computadores vizinhos. Tomando emprestado o ponto de vista de Freedman, Carlsmith e Sears (1970), conforme mencionada anteriormente, pode-se considerar que o projeto proporcionou aos idosos o processo de socialização, coerente com o ambiente em que eles se propuseram a estar, ou seja, o ambiente escolar.

Enquanto realizavam as atividades propostas pelo professor, as alunas interagiam entre si, muitas vezes, ajudando umas às outras, ação que neste artigo é chamada de solidariedade. A solidariedade dava-se, sobretudo, entre aquelas que já se conheciam, mas também era um fator que auxiliava a aproximação.

No tocante às suas atitudes durante as atividades, o professor sempre estava atento às dificuldades das estudantes ao realizarem as tarefas e sempre se dispunha a ajudá-las individualmente. Quando as alunas realizavam a atividade proposta com sucesso, o professor elogiava e incentivava. De acordo com Senos e Diniz (1998), o reconhecimento por uma atividade bem feita leva a que o próprio aluno reconheça sua capacidade e assuma níveis de autoestima favoráveis para o desenvolvimento e o investimento no aprendizado, tornando-se mais seguro de sua capacidade e de sua potencialidade.

A capacidade de usar as TICs de forma crítica e efetiva provocava expressões de alegria quando as alunas realizavam as atividades com êxito. Foram observados sorrisos, necessidade de compartilhar com a colega mais próxima, alegria, comemoração e automotivação para novos desafios quanto ao aprendizado das TICs. Esse sentimento foi chamado de autoestima por Luzzi (2006), Xavier (2007), Fraquelli (2008), Bersch (2009), Kachar (2009), Griebler, Rokoski e Dalri (2010), Marcon (2010), Wolf et al. (2010), Granda e Duarte (2011), Ordones, Yassuda e Cachioni (2011), Passos e Abreu (2011), Pereira e Neves (2011) e Bolzan, Oliveira e Löbler (2013), que, em seus estudos, identificaram o mesmo. 
Passos e Abreu (2011) discutem que a inclusão digital pode promover melhoria da autoestima, fazendo os idosos sentirem-se valorizados perante a família e a sociedade.

\section{Conclusão}

Como contribuições, esta etnografia apresentou descobertas acerca dos bastidores do processo de inclusão digital de idosos e os estudos sobre esse tema. Mostrou um processo de socialização entre os alunos, que resultou em afetividade. Emergiu, desse campo, também, a solidariedade, expressa durante alguma atividade por meio da oferta de ajuda mútua.

No que se refere aos fatores que implicaram no processo de inclusão digital de idosos, destacam-se a didática do educador, a necessidade do treinamento utilizando um objeto de aprendizagem, um ambiente propício para a aprendizagem, a oportunidade de sanar as dúvidas e o incentivo para construir o conhecimento. Quanto ao impacto da inclusão digital na vida dos idosos, foi possível perceber o aumento do nível de sua autoestima. Os indivíduos que participaram da proposta da política pública tornaram-se mais confiantes diante da tecnologia, da sociedade e da família.

Acerca de sugestões para estudos futuros na área, registra-se a pertinência de comparações entre as políticas públicas de inclusão digital, visando à multiplicação de boas práticas, porém com a devida cautela, salientando a importância da percepção do meio quanto à aplicabilidade destas. Segundo os resultados percebidos nos encontros, nas interações com os beneficiados e os colaboradores da instituição, e também de acordo com as entrevistas, acredita-se que esta pesquisa possa contribuir nessa tarefa.

\section{The girls are on the network: digital inclusion in the third age Abstract}

In this study, we attempted to understand how occurs the process of digital inclusion of older people based on the perceptions of individuals participating in a group of third age that uses digital inclusion as a tool for social inclusion. To reach the objective, we proceeded to an ethnographic research. As results it is pointed out findings such as the generation of affection process and socialization that occurs during the period for the knowledge construction about information and communication technologies (ICTs). Regarding the impact of the digital inclusion in the life of the elderly, it was noticed the increased level of self-esteem. Individuals who participated in the proposal of the public policy have become more confident facing the technology, the society and the family.

Keywords: Digital inclusion. Ethnography. Social inclusion. 


\section{Referências}

AUSUBEL, David Paul. Psicología educativa: un punto de vista cognoscitivo. México: Trillas, 1978.

BERSCH, Lair José. Internet e terceira idade: consumo e efeitos em usuários do extremo oeste do Paraná. 2009. 109 f. Dissertação (Mestrado em Comunicação Social) - Faculdade de Comunicação Social, Pontifícia Universidade Católica do Rio Grande do Sul, Porto Alegre, 2009.

BOLZAN, Larissa Medianeira et al. Validação de um instrumento capaz de identificar o nível de inclusão digital individual. ENCONTRO NACIONAL DA ASSOCIAÇÃO NACIONAL DE PÓS-GRADUAÇÃO E PESQUISA EM ADMINISTRAÇÃO, 36, 2012, Rio de Janeiro. Anais... Rio de Janeiro, 2012.

BURRELL, Gibson; MORGAN, Gareth. Part I: in search of a framework. In:

Sociological paradigms and organisational analysis: elements of sociology of corporate life. London: Heinemann, 1979. p. 1-37.

CASALI, Adriana Machado. Comunicação organizacional: considerações epistemológicas. In: ENCONTRO DA ANPAD, 28, Curitiba, 2004. Anais... Curitiba: Anpad, 2004. p. 1-16.

CAVEDON, Neusa Rolita. Antropologia para administradores. 2. ed. Porto Alegre: Ed. da UFRGS, 2008.

FRANCO, Maria Helena Pereira. Cuidados paliativos e o luto no contexto hospitalar. O mundo da saúde, São Paulo, v. 27, n. 1, 2003.

FRAQUELLI, Ângela Aita. Relação entre autoestima, autoimagem e qualidade de vida em idosos participantes de uma oficina de inclusão digital. 2008. 86 f. Dissertação (Mestrado em Gerontologia Biomédica) - Instituto de Geriatria e Gerontologia, Pontifícia Universidade Católica do Rio Grande do Sul, Porto Alegre, 2008.

FREEDMAN, Jonathan; CARLSMITH, Meril; SEARS, David. Psicologia social. São Paulo: Cultrix, 1970.

FREIRE, Paulo. Pedagogia da autonomia: saberes necessários à prática educativa. São Paulo: Paz e Terra, 2011.

FREITAS, Gabriela Alves; PASSERINO, Liliana Maria. $3^{\text {a }}$ Idade na Rede: ferramentas de comunicação proporcionando a socialização. In: SEMINÁRIO DE PESQUISA EM EDUCAÇÃO DA REGIÃO SUL, 9, 2012, Caxias do Sul, RS. Anais... Caxias do Sul, RS: Anped Sul, 2012. p. 1-16. Disponível em: <http://www.ucs.br/etc/conferencias/index.php/anpedsul/9anpedsul/paper/viewFile/2325/916>. Acesso em: 11 out. 2011.

GOLDFARB, Délia Catulo. Corpo, tempo e envelhecimento. 1997. 96 f. Dissertação (Mestrado em Psicologia Clínica) - Programa de Psicologia Clínica, Pontifícia Universidade Católica de São Paulo, São Paulo, 1997.

GRANDA, Tatiane Krempser; DUARTE, Adriana Bogliolo Sirihal. Inclusão digital na terceira idade: identificando contribuições e lacunas. In: CONGRESSO BRASILEIRO DE BIBLIOTECONOMIA, DOCUMENTAÇÃ̃O E CIÊNCIA DA INFORMAÇÃO, 24, 2011, Maceió. Anais... Maceió, 2011. p. 1-16. Disponível em: http://febab.org.br/congressos/index.php/cbbd/xxiv/paper/ viewFile/196/405. Acesso em: 11 out. 2011.

GRIEBLER, Charlize Naiana; ROKOSKI, Maria Cristina; DALRI, Maidi Terezinha. Digital inclusion experience with visual handicapped. Revista Novas Tecnologias na Educação, Porto Alegre, v. 8, n. 2, p. 1-9, 2010. 
KACHAR, Vitória. Terceira idade \& informática: aprender revelando potencialidades. São Paulo: Cortez, 2003.

Inclusão digital e terceira idade. In: BARROSO, Áurea Eleotério Soares. Novas necessidades de aprendizagem. São Paulo: Secretaria Estadual de Assistência e Desenvolvimento Social; Fundação Padre Anchieta, 2009. p. 11-26.

KOLB, David; RUBIN, Irwin; MCINTYRE, James. Psicologia organizacional: uma abordagem vivencial. São Paulo: Atlas, 1978.

LE BRETON, David. As paixões ordinárias: antropologia das emoções. Trad. de Luís Alberto Salton Peretti. Rio de Janeiro: Vozes, 2009.

LÖBLER, Mauri Löbler et al. Inclusão digital: mapeamento de publicações sobre o tema, na área de Administração. Revista Novas Tecnologias na Educação, Porto Alegre, v. 8, n. 3, p. 1-11, 2011.

LOCATELLI, Patricia Augusta Pospichil Chaves; CAVEDON, Neusa Rolita. As gurias: exercício etnográfico realizado com mulheres idosas praticantes de hidroginástica. Paraná. Ciências Sociais em Perspectivas, v. 10, n. 18, p. 47-61, 2011.

LUZZI, Lérida Zuccarelli. Efeitos da participação em oficinas de inclusão digital sobre o desempenho intelectual e depressão em idosos ativos residentes na comunidade. 2006. 73 f. Dissertação (Mestrado em Gerontologia Biomédica) - Instituto de Geriatria e Gerontologia, Pontifícia Universidade Católica do Rio Grande do Sul, Porto Alegre, 2006.

MALINOWSKI, Bronislaw. Argonautas do Pacífico Ocidental. São Paulo: Abril Cultural, 1978.

MARCON, Karina. Na outra ponta da rede: o interesse dos alunos por projetos de inclusão digital. Revista Novas Tecnologias na Educação, Porto Alegre, v. 10, n. 2, p. 1-10, 2011.

MENDONÇA, Talita Campos; MACEDO, Andréia Borges. A importância do lúdico durante o tratamento fisioterapêutico em pacientes idosos com deficit cognitivo - estudo de caso. Revista Eletrônica "Saúde CESUC" - Centro de Ensino Superior de Catalão, Ano I, n. 1, p. 1-11, 2010.

MORGAN, Gareth. Paradigms, metaphors, and puzzle solving in organization theory. Administrative Science Quarterly, v. 25, n. 4, p. 605-622, 1980.

MURARO, Rose Marie. Os avanços tecnológicos e o futuro da humanidade: querendo ser Deus? Petrópolis, RJ: Vozes, 2009.

ORDONES, Tiago Nascimento; YASSUDA, Mônica Sanches; CACHIONI, Meire. Elderly online: effects of a digital inclusion program in cognitive performance. Archives of Gerontology and Geriatrics, v. 53, n. 2, p. 216-219, 2011.

PASSOS, Janduhy Camilo; ABREU, Marco Aurélio Afonso. A inclusão digital como mecanismo de inclusão social: um olhar sobre os resultados de alguns projetos sociais. In: ENCONTRO DA ANPAD, 35, 2011, Rio de Janeiro. Anais... Rio de Janeiro, 2011. p. 1-16. Disponível em: <http://www.anpad.org.br/evento.php?acao=trabalho\&cod_edicao_subsecao=736\&cod_evento_ edicao $=58 \&$ cod_edicao_trabalho $=12977 \geq$. Acesso em: 08 set. 2011.

PEREIRA, Cláudio; NEVES, Rui. Os idosos e as TIC: competências de comunicação e qualidade de vida. Revista Kairós Gerontologia, São Paulo, v. 14, n. 1, p. 5-26, 2011.

SENOS, Jorge; DINIZ, Tereza. Crianças e jovens sobredotados: intervenção educativa. Brasília: Ministério da Educação/Departamento do Ensino Básico, 1998.

WACQUANT, Loic. Corpo e alma: notas etnográficas de um aprendiz de boxe. Rio de Janeiro: Relume Dumará, 2002. 
WEHMEYER, Cláudia de Oliveira Tacques. O ensino com uso de recursos informatizados na aprendizagem da língua espanhola por idosos. 2006. 97 f. Dissertação (Mestrado em Gerontologia Biomédica) - Instituto de Geriatria e Gerontologia, Pontifícia Universidade Católica do Rio Grande do Sul, Porto Alegre, 2006.

WOLF, Tânea Maria et al. O empoderamento de mulheres através da inclusão digital. Inclusão Social, Brasília, v. 3, n. 2, p. 106-122, 2009.

XAVIER, Selma Lúcia da Costa. Afetividade e inclusão digital: um estudo de caso em uma universidade particular. Revista Digital CVA, Canoas, v. 4, n. 3, p. 1-14, 2007. 